\title{
La difusión del patrimonio paleontológico. La experiencia con el legado personal de Bartomeu Darder i Pericàs
}

\begin{abstract}
En 2013 se puso en marcha la web que recoge el legado de Bartomeu Darder i Pericàs (1894-1944), geólogo y paleontólogo mallorquín muy activo en el primer tercio del siglo XX. Tras la donación del fondo personal del científico realizada por su hijo Josep Darder a la Comunidad Autónoma de las Islas Baleares, se inician las tareas de sistematización y difusión. La primera fase de digitalización y catalogación archivística de cuadernos de campo y fotografías finaliza con la creación del sitio http://legatdarder. balearsfaciencia.org que pone al alcance del usuario estos materiales, además de información sobre la biografía y la obra de Bartomeu Darder.
\end{abstract}

Francesc X. Bonnín Salamanca | Arxiu del So i de la Imatge de Mallorca

María Sebastián Sebastián | Universitat de les Illes Balears

URL de la contribución <www.iaph.es/revistaph/index.php/revistaph/article/view/4187>

Bartomeu Darder Pericàs (Palma, 1894-Tarragona, 1944) fue uno de los científicos mallorquines más destacados y con más proyección internacional de la primera mitad del siglo XX. Desde las disciplinas de la geología, la paleontología y la hidrología, se dedicó sin descanso y con pasión a la investigación, a la docencia y a la divulgación. Referente científico y humano en la sociedad mallorquina de la época, fue el causante de un avance sustantivo del conocimiento geológico de la isla y del levante peninsular, así como de su difusión. Fue colaborador y continuador del trabajo del científico francés Paul Fallot (1889-1960), lo que abrió las puertas de su carrera. Su participación en el XIV Congreso Geológico Internacional (Madrid, 1926) le otorgó reconocimiento entre sus colegas y la posibilidad de la publicación y difusión de sus investigaciones en el ámbito europeo.

El fondo documental y fotográfico acumulado por el científico mallorquín durante su trayectoria profesional fue conservado en el despacho profesional de su hijo, el también geólogo e hidrólogo Josep Darder Seguí (1925-2008), que en el año 2007 donó desinteresadamente todos los materiales a la Comunidad Autónoma de las Islas Baleares (CAIB). La Dirección General de Universidades, Investigación y Transferencia del Conocimiento (DGURT) de la Consejería de Educación,
Cultura y Universidades del Gobierno de las Islas Baleares asumió la donación y puso en marcha un plan para su preservación, catalogación y difusión, que contó con la participación de diferentes profesionales de la Universitat de les Illes Balears, la misma Consejería y colaboradores independientes.

El legado Bartomeu Darder Pericàs permite documentar la actividad científica del productor, su labor investigadora y docente y su participación en diferentes organismos y sociedades relacionadas con el mundo de la geología desde diferentes ámbitos, tanto a nivel nacional como internacional. Está formado por cuadernos de campo, separatas, mapas, libros y revistas de geología, paleontología y otras disciplinas científicas, y por un destacable fondo fotográfico de producción propia.

La digitalización del legado, que en una primera fase se ha ceñido a los cuadernos de campo y las fotografías, se ha realizado como medida de preservación del mismo y a la vez como el medio más directo para obtener su difusión y accesibilidad. La conversión digital es una tarea compleja, sobre todo en el caso de los materiales fotográficos. Para realizarla con el máximo de fidelidad y precisión, se han aplicado pautas adaptadas a los protocolos y estándares de las instituciones de referencia en el ámbito de la conservación documental. 
Tras la digitalización se ha llevado a cabo la catalogación con dos objetivos principales. Por una parte, sistematizar rigurosamente la introducción de información; por otra, facilitar su búsqueda posterior teniendo en cuenta que todo el material tenía que estar disponible en una web $y$, por tanto, al alcance de un público muy amplio que podía ser general o especializado.

La base de datos se ha diseñado con un programa informático (Filemaker) y se organiza en dos secciones, cuadernos de campo y fotografías, que corresponden a los materiales gestionados en la primera fase del plan de conservación y difusión. Para cada una de ellas se crea una ficha tipo organizada por áreas según se establece en las normas ISAD (Norma Internacional General de Descripción Archivística) e ISAAR (Registros de Autoridad de Archivos Relativos a Instituciones, Personas y Familias). En las destinadas a los cuadernos de campo se recogen los topónimos y los nombres de personas que acompañan a Darder y se indica qué dibujos ilustran el texto. Las del fondo fotográfico se centran en la identificación de la imagen. Es un trabajo complejo debido a la gran diversidad de temas plasmados (aspectos geológicos, fósiles, retratos, imágenes de Mallorca y de otros lugares). Tan sólo un pequeño número de placas llevaba una inscripción relativa al lugar de toma, por lo que fue necesario un trabajo de investigación y documentación con el asesoramiento del Doctor Joan J. Fornós en las algo más de doscientas imágenes de fósiles. El trabajo se ha complementado con el establecimiento de relaciones entre fotografías, que en ocasiones han podido unirse reconstruyendo panorámicas, y con los bocetos que complementan el texto de los cuadernos de campo.

Para culminar los objetivos de difusión y accesibilidad del Legado de Bartomeu Darder Pericàs se ha desarrollado una página web en cooperación con los técnicos de la Fundación Bit (Fundación Balear de Innovación y Tecnología), organismo público vinculado a la CAIB. El diseño en cascada de la interfaz y el uso del sistema ICA-ATOM, un software libre específico para bases de datos para catálogos archivísticos, permiten compaginar varios niveles de lectura sobre los diferentes fondos, siendo tanto una herramienta para investigadores como un canal de divulgación para público general.

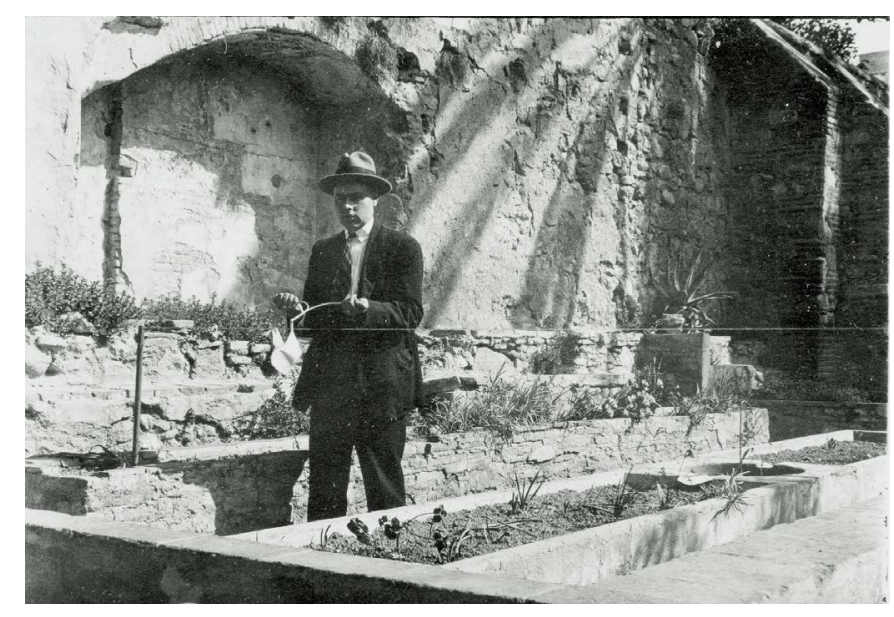

Bartomeu Darder haciendo experimentaciones en torno a los zahoríes. Positivo sobre papel. Gelatina de plata. 1923-1944 | fotos Llegat Darder (CAIB), titular de todas las imágenes que ilustran este texto

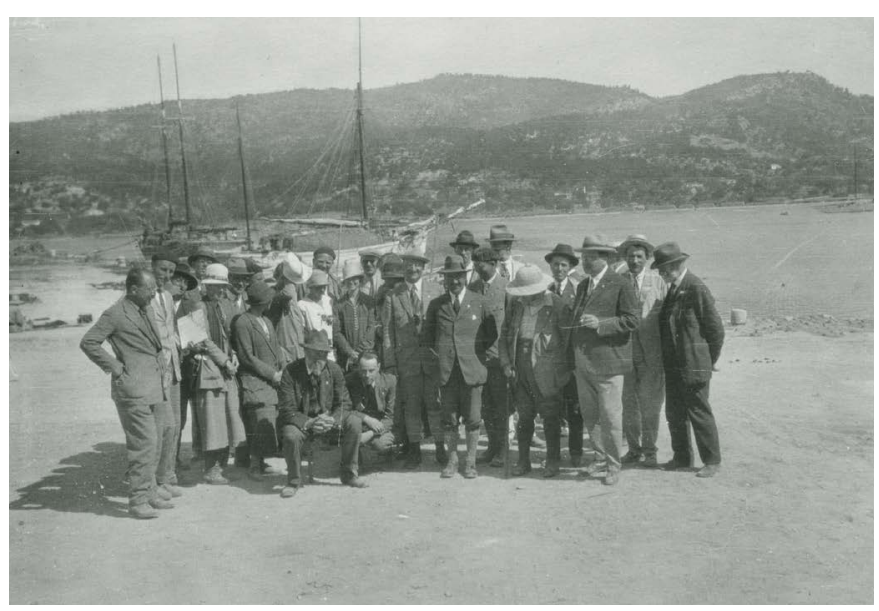

Participantes del XIV Congreso Internacional de Geología. Positivo sobre papel. Gelatina de plata. 11 de junio de 1926

Desde la entrada en funcionamiento del sitio web (http:// llegatdarder.balearsfaciencia.org/), otras páginas se han hecho eco de su apertura y en la actualidad aparece referenciada por instituciones como la Associació de Geòlegs de les Illes Balears. Asimismo, la amplitud del legado y su disponibilidad en abierto permiten su utilización por parte de investigadores de disciplinas muy amplias, desde la paleontología o la geología hasta la historia del arte.

La experiencia llevada a cabo con el fondo personal de Bartomeu Darder pone de manifiesto la importancia de conservar, sistematizar y, sobre todo, difundir el 

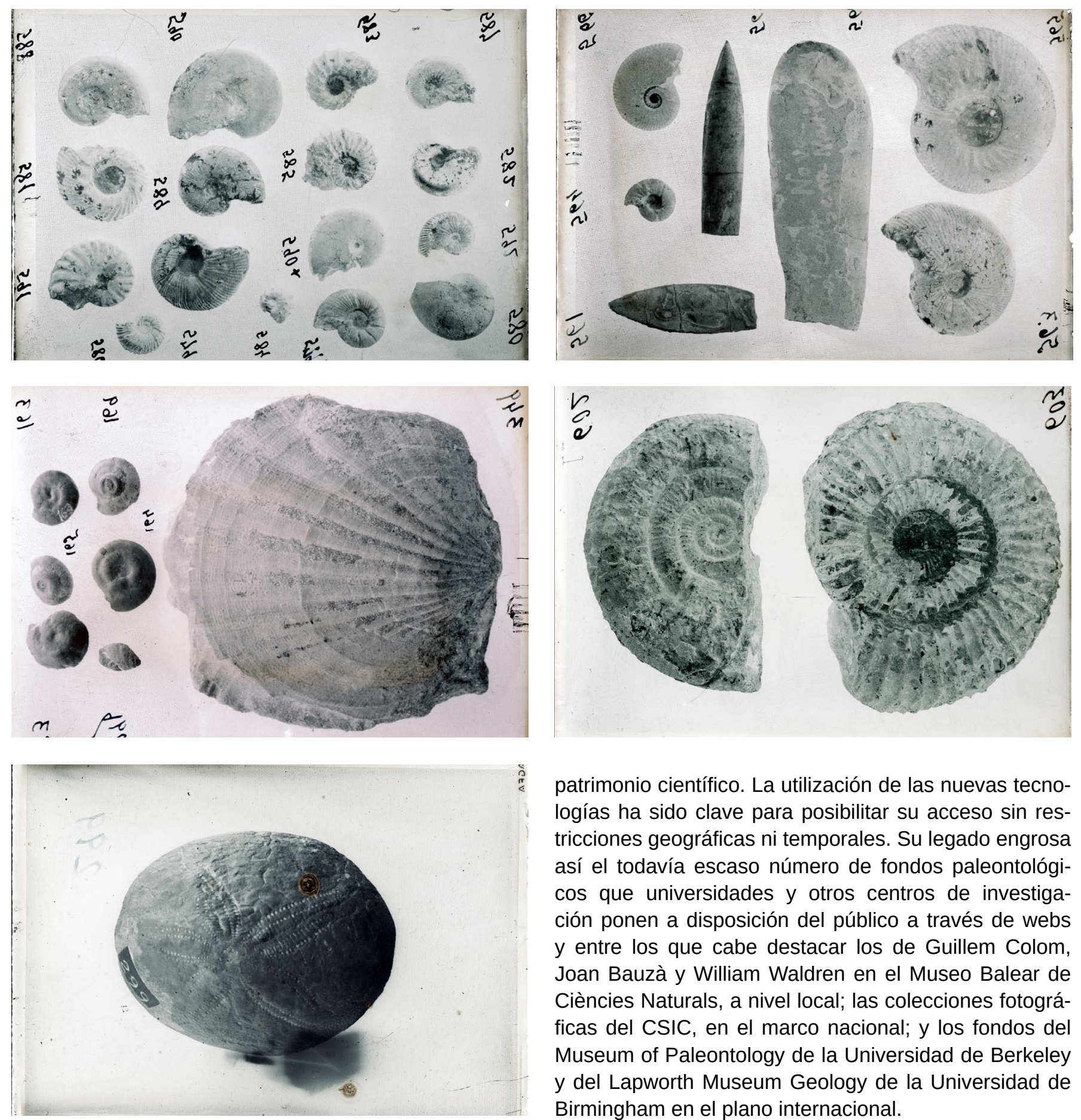

patrimonio científico. La utilización de las nuevas tecnologías ha sido clave para posibilitar su acceso sin restricciones geográficas ni temporales. Su legado engrosa así el todavía escaso número de fondos paleontológicos que universidades y otros centros de investigación ponen a disposición del público a través de webs y entre los que cabe destacar los de Guillem Colom, Joan Bauzà y William Waldren en el Museo Balear de Ciències Naturals, a nivel local; las colecciones fotográficas del CSIC, en el marco nacional; y los fondos del Museum of Paleontology de la Universidad de Berkeley y del Lapworth Museum Geology de la Universidad de Birmingham en el plano internacional.

Fósiles. Negativos sobre placa de vidrio. Gelatina de plata, 1910-1944 